\title{
Diagnosis of Short-circuits in Induction Motor Stator Winding Using a Modified Park Transformation
}

Research Article

\author{
Grzegorz Tarchała*, Marcin Wolkiewicz, Mateusz Krzysztofiak \\ Wrocław University of Science and Technology, Wybrzeże Wyspiańskiego 27, 50-370 Wrocław, Poland
}

Received: September 05, 2020; Accepted: September 14, 2020

\begin{abstract}
This paper deals with a novel diagnostic method for finding the stator winding short-circuit damage of induction motor drives. The proposed method is based on a new, simple idea of applying a modified, triple Park transform instead of using a computationally demanding on-line Fast Fourier Transform (FFT) analysis. The diagnostic method is based on the analysis of current and reference voltage vector components, whicharethepartofthe DirectField Oriented Controlstructure. The proposed method is verified experimentally using tests results. Further, the influence of speed, loadtorque and the parameters of PIregulators onthe performance of the proposed diagnostic method arealso discussed.
\end{abstract}

Keywords: induction motor • damage diagnostics • shorted turns • Park's transformation

\section{Introduction}

Induction motors, supplied by industrial frequency converters, are the most commonly used existing drive systems in industry (Orłowska-Kowalska and Dybkowski, 2016). Motor failure may result in stopping of various operational activities of a company leading to heavy loss and so its diagnostics is becoming an increasingly important issue.

Most failures that occur in induction motors are due to bearing failures (Grubic et al., 2008; Riera-Guasp et al., 2015), while electrical failure is the second most common cause of motor damage (up to $40 \%$ of all damage).

There are many methods for monitoring and diagnosing the induction motor stator winding damages working both in the case of mains-supplied (Cruz and Cardoso, 2001) and frequency converter-supplied with scalar control $u / f=$ constant (Diallo et al., 2005; Drif and Marques Cardoso, 2014; Gandhi et al., 2011; Wolkiewicz et al., 2015).

The issue of diagnosing the electrical damages of an induction motor, operating in a closed control loop, is not frequently analysed in the literature (Bellini et al., 2000; Cruz and Cardoso, 2004; Seshadrinath et al., 2014; Wolkiewicz et al., 2016, 2017). However, it is important because the control system with regulators and feedbacks has compensative properties for the occurring damage (Bednarz, 2017; Bellini et al., 2000). Moreover, when comparing the closed loop control to both mains-powered or scalar control systems, the damage symptoms can appear not only in currents but also in the voltages generated by the control system (Wolkiewicz et al., 2016). Depending on the used control system, the sensitivity of the damage diagnostic indicators may be also different (Wolkiewicz et al., 2017).

Most of the proposed diagnostic solutions for motor windings are based on spectral analysis and searching for diagnostic frequencies in the frequency range (Bellini etal., 2000; Cruz and Cardoso, 2001, 2004; Diallo etal., 2005; Drif and Marques Cardoso, 2014; Gandhi et al., 2011; Wolkiewicz et al., 2015, 2016, 2017) or using other complex methods including wavelet analysis (Seshadrinath et al., 2014). Characteristic frequencies are sought in both currents (Cruz and Cardoso, 2004), voltages (Wolkiewicz et al., 2016) and other signals, for example, signals of instantaneous active 
and passive power (Drif and Marques Cardoso, 2014). However, spectral analysis is computationally time-consuming and requires the implementation of additional algorithms in industrial converters requiring processors with large computing power.

Boileau et al. (2013) proposed a simple diagnostic method of stator windings for permanent magnet synchronous motor (PMSM) which may allow to automatically determine the amplitude of the second harmonic voltage signals without any requirement of using the spectral analysis. The authors suggest the use of a modified, double Park Transform of voltage signals recorded in a synchronous system, and the determination of received signals' DC components. Until now, the proposed diagnostic method has not been used in the diagnostics of induction motors.

Based on the above analysis, this paper presents a new method which uses the modified Park Transform in the diagnostics of the induction motor with particular emphasis on the damage due to shorted-turns of the stator winding. On the contrary to Boileau et al. (2013), the Park's triple (not double) transformation and extraction of DC components from both voltage and current (not only voltage) signals are proposed.

The next section of the paper presents the field-oriented control system through which the proposed diagnostic system works. Afterwards, the effects of the induction motor, its operation in a closed control system and stator winding shorted turns damage are described. Then, the subsequent section presents the suggested diagnostic method. Next, the experimental setup and the test results obtained with it are described. Finally, the paper is summarised.

\section{DFOC system of induction motor}

Induction motor control systems used in the industry are supposed to have high static and dynamical properties. The classical vector control method - Direct Field Oriented Control (DFOC) - is applied to meet these requirements. It should be noted that the systems operating in a closed control loop compensate initial phases of motor damage, which makes the diagnostics in such systems more difficult than in the case of scalar control.

The scheme of the induction motor vector control system used is presented in Figure 1. The control system consists of four PI-type controllers, rotor flux estimator and a voltage modulator (Space Vector Modulation (SVM)). Field-oriented control consists in controlling the values of the stator current vector components, where the $i_{s x}$ current component is responsible for the value of the rotor flux amplitude, while the $i_{s y}$ component is responsible for generating the electromagnetic torque. The concept of such control refers to control of separately excited DC machine.

Determination of the reference values of individual components of the current vector is carried out by superior flux and speed regulators. The difference between measured speed $\omega_{m}$, and reference speed $\omega_{m}^{\text {ref }}$, is fed to the speed controller. The same happens in the flux regulator, where the rotor flux setpoint $\psi_{r}^{r e f}$ is compared with the

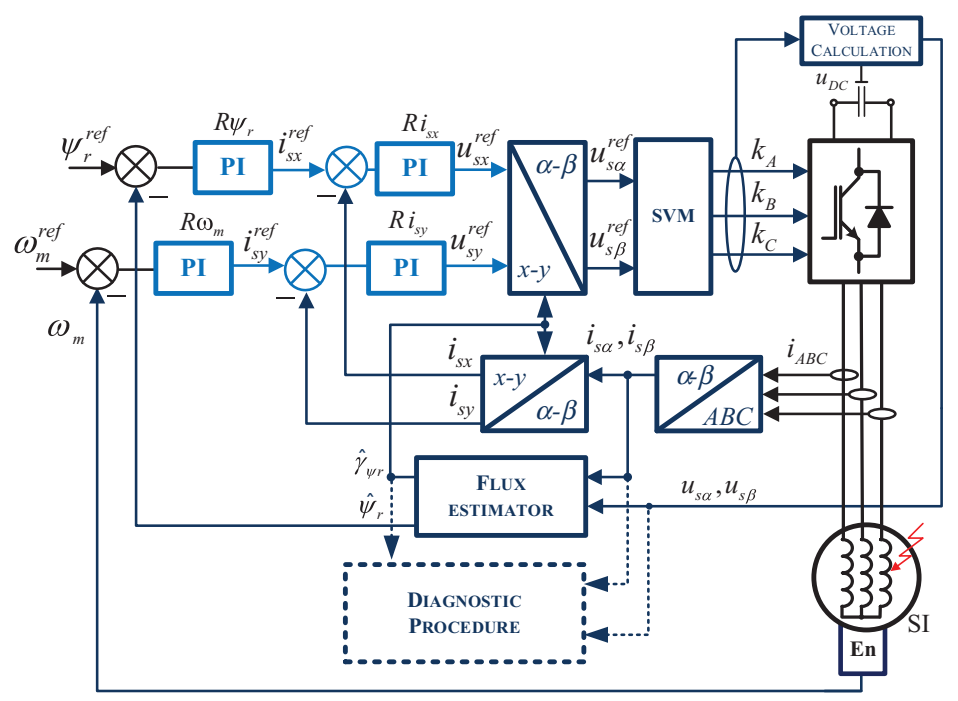

Fig. 1. Direct rotor field oriented control system for induction motor. 
estimated value of the rotor flux amplitude $\hat{\psi}_{r}$. The stator current component regulation errors are the inputs of the current regulators, which are output signals here that are transformed into the stationary frame, and then become the input signals for the SVM modulator.

Apart from the amplitude value of the flux vector $\psi_{r}$, the estimator determines also the position angle of the rotor vector $\gamma_{\psi r}$, which is necessary for proper transformation between coordinate systems. The flux estimator requires values of stator current as well as stator voltage components. The voltage is determined based on the DC bus voltage $u_{D C}$ and the control signals of the transistors (control signal duty cycles).

The diagnostic system uses the components of the stator current vector and the components of the voltage vector in stationary system, which are subjected to appropriate transformations. Based on that, the degree of the stator damage was analysed.

\section{Winding shorted turns damage in a field-oriented control system of an induction motor}

The occurrence of winding short-circuits in the stator windings of an induction motor causes the asymmetry of the motor windings and, therefore, the third harmonics appear in phase currents of the motor with amplitudes of $I_{d A}, I_{d B}$, $I_{d C}$, and phase shifts $\theta_{d A}, \theta_{d B}, \theta_{d C}$ relative to the first harmonics of currents (Bellini et al., 2008). Moreover, the motor phase currents also become asymmetrical:

$$
\left\{\begin{array}{l}
i_{S A}=I_{s A} \cos (\omega t+\delta)+I_{d A} \cos \left(3 \omega t+\theta_{d A}\right) \\
i_{s B}=I_{s B} \cos \left(\omega t+\delta-\frac{2 \pi}{3}\right)+I_{d B} \cos \left(3 \omega t+\theta_{d B}-\frac{2 \pi}{3}\right) \\
i_{S C}=I_{s C} \cos \left(\omega t+\delta+\frac{2 \pi}{3}\right)+I_{d C} \cos \left(3 \omega t+\theta_{d C}+\frac{2 \pi}{3}\right)
\end{array}\right.
$$

where: $I_{s A}, I_{s B}, I_{s C}-$ amplitudes of the first harmonics of phase currents, $\omega=2 \pi f$ - synchronous velocity, $f$ - phase currents frequency, $\delta$ - power angle, phase shift between the rotor flux and the stator current of the induction motor. Equation (1) applies to motor damage in each of the motor phases, the effect of these damages can be seen in different phase shift angles between the respective harmonics.

Because of the small differences between amplitudes and phase shifts (Bellini et al., 2008), the following approximation is adopted in the remaining part of the paper: $I_{s}=I_{s A}=I_{s B}=I_{s C}, I_{d}=I_{d A}=I_{d B}=I_{d C}$ and $\theta_{d}=\theta_{d A}$ $=\theta_{d B}=\theta_{d C}$.

If phase currents in the faulted state Eq. (1) are transformed to the $\alpha-\beta$ stationary frame using the Clarke transform, the components of the current vector will change to the following form:

$$
\left\{\begin{array}{l}
i_{s \alpha}=I_{s} \cos (\omega t+\delta)+I_{d} \cos \left(3 \omega t+\theta_{d}\right) \\
i_{s \beta}=I_{s} \sin (\omega t+\delta)+I_{d} \sin \left(3 \omega t+\theta_{d}\right)
\end{array}\right.
$$

In this system, the $\alpha$ and $\beta$ current components are also characterised by the presence of a third harmonic. However, if the classic Park transformation is used, the currents in the $x-y$ synchronous system-oriented according to the rotor flux space vector take the form:

$$
\left\{\begin{array}{l}
i_{s x}=I_{s} \cos \delta-I_{d} \cos \left(2 \omega t+\theta_{d}\right) \\
i_{s y}=I_{s} \sin \delta+I_{d} \sin \left(2 \omega t+\theta_{d}\right)
\end{array}\right.
$$

Thus, according to Eq. (3), time-constant and pulsating signals appear in the stator current vector component waveforms in the field-oriented frame. The time-constant signals depend on the desired values of the rotor flux 
amplitude and the electromagnetic torque of the motor. The damage components pulsate with a double supply frequency.

An example of an Fast Fourier Transform (FFT) analysis of the current and the reference voltage vector component waveforms in the $x$-axis is shown in Figure 2. A fundamental and third components, which do not change their amplitudes with the increasing degree of damage (increasing $N_{s h}$ ) can be noticed. However, the $2 f_{s}$ component can be observed, where amplitude increases significantly with $N_{s h}$.

Due to the operation of the control structure, based on feedbacks and PI controllers, the field-oriented control system exhibits compensatory action compared to the scalar control system operating at a constant ratio of voltage amplitude and frequency $u / f=$ constant. Therefore, the effect of the damage, visible in the phase currents will be compensated by the control system, by appropriately modified voltages. Thus, the double frequency harmonic signals will appear in the components' waveform of the voltage vector in the $x-y$ frame. The second dominant harmonic will be transformed into the third harmonic in the stationary system, by using the Park's inverse transform in a similar way to stator currents.

\section{Suggested diagnostic method for the winding shorted turns damage of an induction motor stator}

As mentioned above, the waveforms of phase currents and current vector components in the $\alpha$ and $\beta$ axes in the event of damage to the stator winding are characterised by the formation of the third harmonic of the fundamental frequency. The amplitude of the third harmonic is, therefore, a good diagnostic indicator based on which one can conclude about the damage occurred. However, direct determination of the damage requires a time-consuming FFT analysis and definition of the fundamental frequency value.

Further, the modified triple Park transformation is used to isolate the value of the damage component without using the spectral analysis of the diagnostic signal and can be presented in the form:

$$
\left\{\begin{array}{l}
i_{s x 3}=i_{s \alpha} \cos (3 \omega t)+i_{s \beta} \sin (3 \omega t) \\
i_{s y 3}=-i_{s \alpha} \sin (3 \omega t)+i_{s \beta} \cos (3 \omega t)
\end{array}\right.
$$

where: in steady state $\omega t=\hat{\gamma}_{\psi r}$ and $i_{s \times 3}, i_{s y 3}$ - components of the stator current vector in the new $x_{3}-y_{3}$ coordinate system, which is rotating with triple basic velocity.

By modifying Eqs (2) and (4), the following equation is obtained:

a)

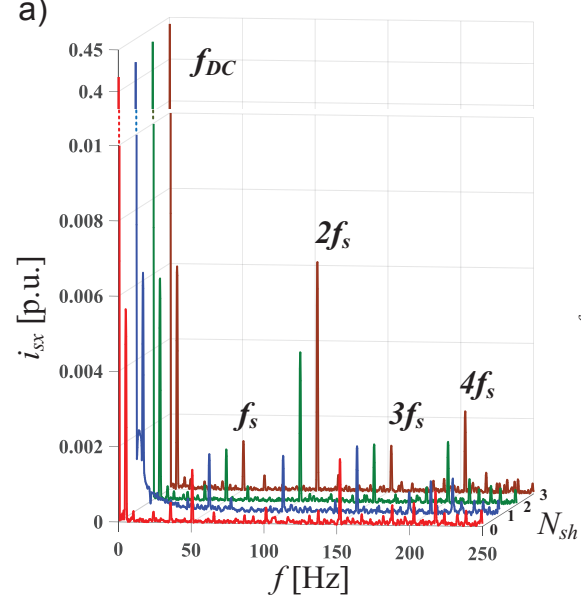

b)

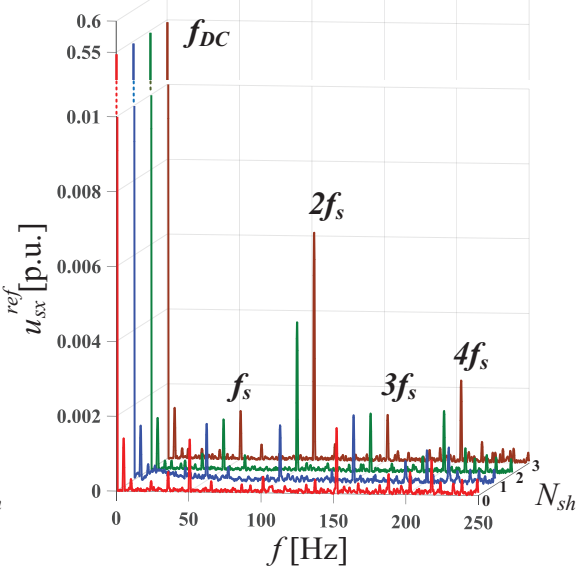

Fig. 2. Example of spectral analysis of: (a) the stator current in the $x$-axis, (b) the reference voltage in the $x$-axis for field-oriented control of an induction motor in the case of a low number of shorted turns $\left(N_{\text {sh }}=0,1,2,3\right)$. 


$$
\left\{\begin{array}{l}
i_{s x 3}=\underbrace{I_{i s x} 3 D C}_{I_{d} \cos \theta_{d}}+I_{s} \cos (2 \omega t-\delta) \\
i_{s y 3}=\underbrace{I_{d} \sin \theta_{d}}_{i s y 3 D C}-I_{s} \sin (2 \omega t-\delta)
\end{array}\right.
$$

Based on Eq. (5), it is observed that the analysed signals consist of the constant components $i_{s \times 3 D C}$ and $i_{s y 3 D C}$, related to the damage and pulsating components with a twice the basic velocity.

Isolation of DC components can be done using a suitable low-pass filter or any other method. In this study, in order to isolate the DC components, the average value of 250 samples of the signal was calculated, using the Hann window (a ready to use tool from the LabView library).

After the separation of the DC parts from the current vector components written in the $x_{3}-y_{3}$ system (5), the following fault indicator $(\mathrm{FI})$ can be proposed:

$$
F I_{i}=\sqrt{i_{s x 3 D C}^{2}+i_{s y 3 D C}^{2}}=I_{d}
$$

The theoretical analysis presented above is illustrated in Figure 3. It is shown that in the case of stator phase current, third harmonics amplitude raises significantly (Figure 3a). Further, as a result, the second harmonic amplitude of $x$-axis current vector component increases after the fault occurs (Figure $3 b$ ). Finally, the $x_{3}$-axis component has only the DC part when the stator winding is damaged.

Asmentioned in the previous section, the DFOC system has a compensative mechanismforany damage thatoccurs. The system tends to force constant current signals in the $x-y$ coordinate system in a steady state, i.e. $i_{s x}^{\text {ref }}, i_{s y}^{\text {ref }}=$ constant (constant load torque and constant amplitude of the rotor flux). This causes that the currents in the $\alpha-\beta$ frame are close to sinusoidal. Thus, internal regulators of current components tend to obtain currents without higher harmonics $\left(I_{d}\right.$ minimisation in Eq. (6)) by appropriate modification of the reference voltages. The performance of this action depends on the values of the controllers' parameters, as shown in one of the following sections. So, as in the case of currents, voltages in the $\alpha-\beta$ system will include a third harmonic that appears in the case of damage to the induction motor windings.

Using the modified Park transformation Eq. (4) and appropriate extraction of the DC voltage components of the failure signals, one can obtain a voltage Fl, written similarly to Eq. (6):

$$
F I_{u}=\sqrt{u_{s x 3 D C}^{2}+u_{s y 3 D C}^{2}}
$$

The $\mathrm{Fl}_{i}$ current and $\mathrm{Fl}_{u}$ voltage Fls have the following features:

- no need to calculate spectral analysis (FFT); it is not required to determine first the basic frequency and then the amplitude of double (or triple) harmonic of the respective signals,

- they do not depend on the power angle $\delta$, nor on the angle of shift of the current's third harmonic relatively to the first harmonic $\theta_{d^{\prime}}$

- they also do not depend on the place of damage (motor phase).

a)

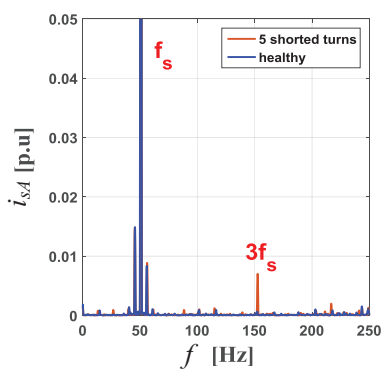

b)

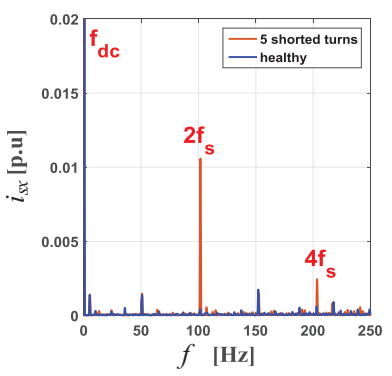

c)

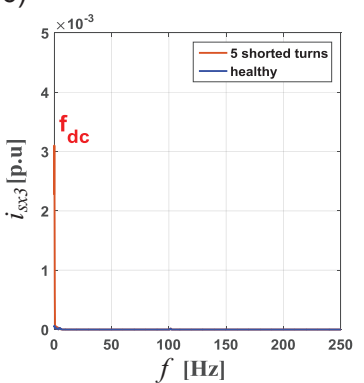

Fig. 3. Comparison of spectral analysis for the healthy and damaged motor ( 5 shorted turns): (a) stator phase current, (b) $x$-axis component of stator current vector, (c) $x_{3}$-axis component of stator current vector; nominal speed and torque. 
A block diagram of the proposed diagnostic method is shown in Figure 4. This procedure requires knowledge of the signals of current and voltage vector components in the stationary coordinate system and the estimated rotor flux angle, which are required to carry out the modified triple Park transform $P\left(3 \hat{\gamma}_{\psi r}\right)$. Then, the extraction of the DC components is carried out and the amplitude of the resulting proposed diagnostic indicators is calculated. The value of the indicators can be used to infer about the state of the machine, which can be done, for example, by comparing to the initial value (threshold value). This value can be determined during the process of identifying machine parameters, which is necessary in the case of vector control systems - this procedure is implemented in most industrial frequency converters.

\section{Experimental setup}

The motor used in this research is an induction motor, Indukta Sg 100L-4B, $3 \mathrm{~kW}$, with a special design, enabling modelling of stator winding shorted turns damage in each phase of the motor. The tested motor was specially rewound to allow testing the stator failures. Specific numbers of turns were connected to the connection plate, as shown in Figure 5. The system allows shortage of several turns of the stator winding, carried out by making the connection with or without including an additional resistance. In this research, the tests have been conducted using a metallic connection. Based on this, the tests are limited to 5 shorted turns that constitutes about $3 \%$ of the whole winding.

The experimental tests were conducted using the test setup presented in Figure 6. This motor is connected via a clutch to the Lenze MCS14H32 synchronous motor, enabling the generation of the load torque. The induction motor is supplied by a $5.5 \mathrm{~kW}$ TWERD MFC 710 frequency inverter with a two-level voltage inverter controlled through fibre optic cables. On the other hand, the synchronous motor is supplied by a Lenze 8400 inverter. The system

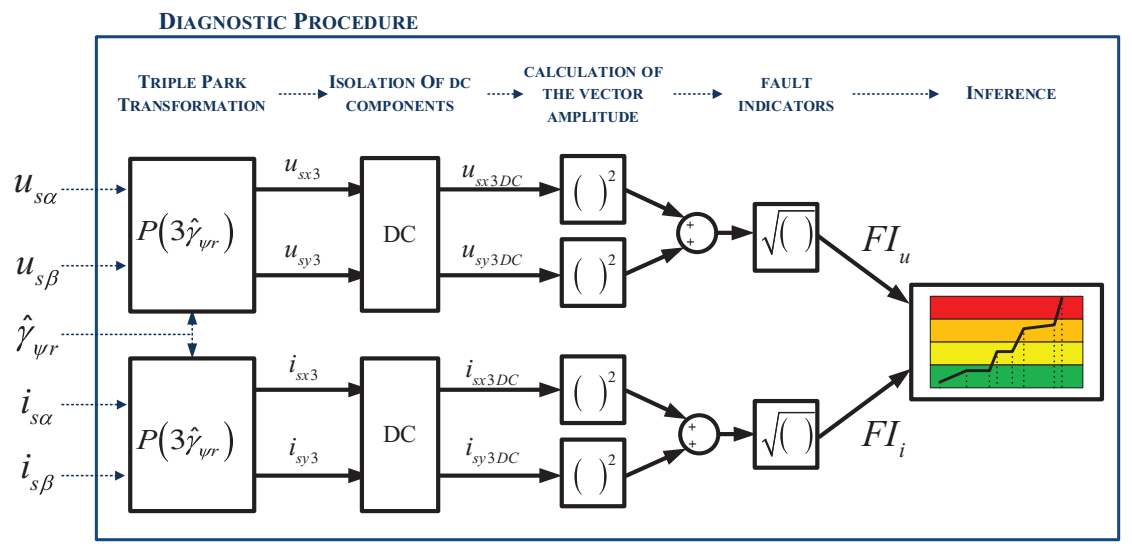

Fig. 4. Block diagram of the proposed diagnostic system.

a)

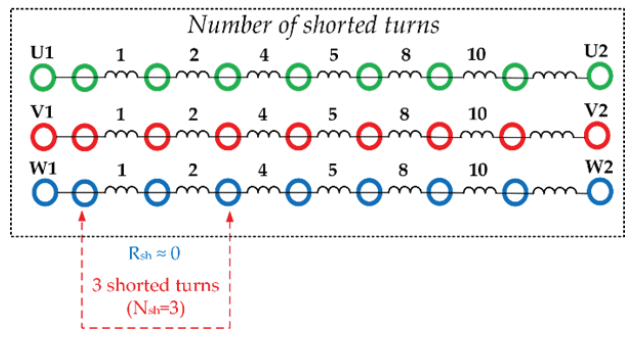

b)

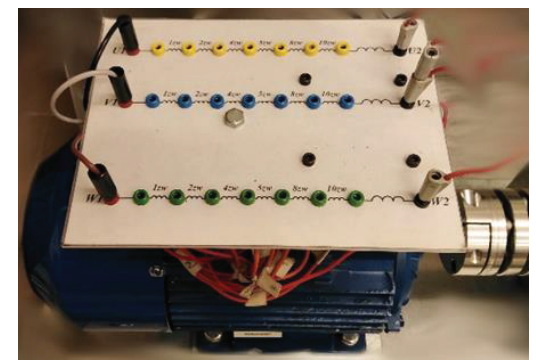

Fig. 5. Specially prepared induction motor: (a) schematic diagram of the connection plate with an example of 3 shorted turns, (b) photo of the motor under test. 
is also equipped with an incremental encoder and a resolver, allowing the measurement of the drive speed and position of the shaft. LEM transducers were used to measure the currents $i_{S A}, i_{s B}, i_{s C}$ of the induction motor and the DC bus voltage $u_{D C}$ of the TWERD voltage source inverter.

The control and diagnostic structure is implemented on a rapid prototyping system using the National Instruments PXI system. The direct rotor field-oriented control structure was used to control the induction motor. The control system uses signals from the transducers, i.e. phase currents $i_{S A}, i_{s B}, i_{s C}$, rotational speed $\omega_{m}$ and the $u_{D C}$ voltage. The output signals are the digital signals $k_{A}, k_{B}, k_{C}$ that control the voltage inverter switches and the required load torque value $m_{o}^{\text {ref }}$.

The software used was VeriStand for process control and visualisation, Simulink for control system preparation and LabView for system diagnostics.

\section{Experimental test results}

Using the test setup described in the previous section, a series of tests were performed to evaluate the proposed diagnostic method. A special attention was paid to the analysis of the impact of the actual drive speed and load torque on the proposed damage indicator. The impact of the parameters of PI controllers on the value of obtained FI diagnostic indicators was analysed as well.

All test results presented are related to a short circuit in motor phase $A$, however, comparative tests show that the results for the remaining motor phases are also similar.

\subsection{Diagnostic indicator waveforms under varying load torque conditions}

Figure 7 shows the results of the on-line work of the proposed diagnostic procedure under the conditions of the stepwise load torque changes and constant, rated motor speed. The course of the set load torque is shown in Figures $7 \mathrm{a}$ and $7 \mathrm{~b}$ - it increases from the minimum to the nominal value in steps, changing by $0.2 m_{N}$ every $6 \mathrm{~s}$.

Waveforms of state variables of the field-oriented control system are shown in Figures 7c and 7d, respectively. They are the components of the current vector and stator voltage. It can be clearly noted that the principle of DFOC vector control is fulfilled' the $i_{s x}$ component responsible for generating the rotor flux is constant over time, while the

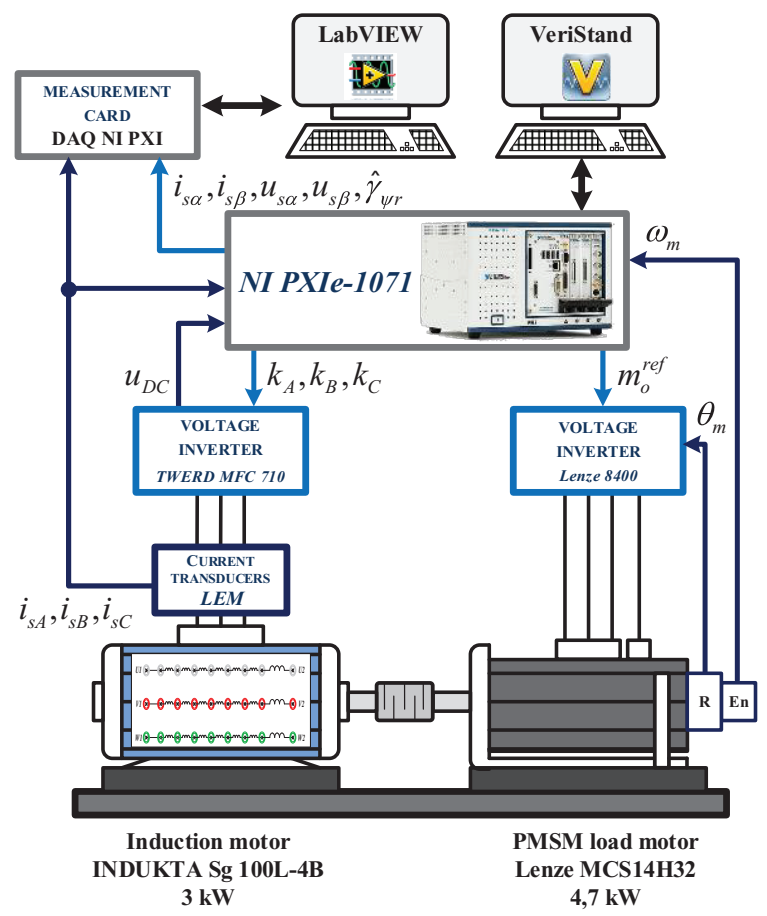

Fig. 6. Block diagram of the experimental setup. 

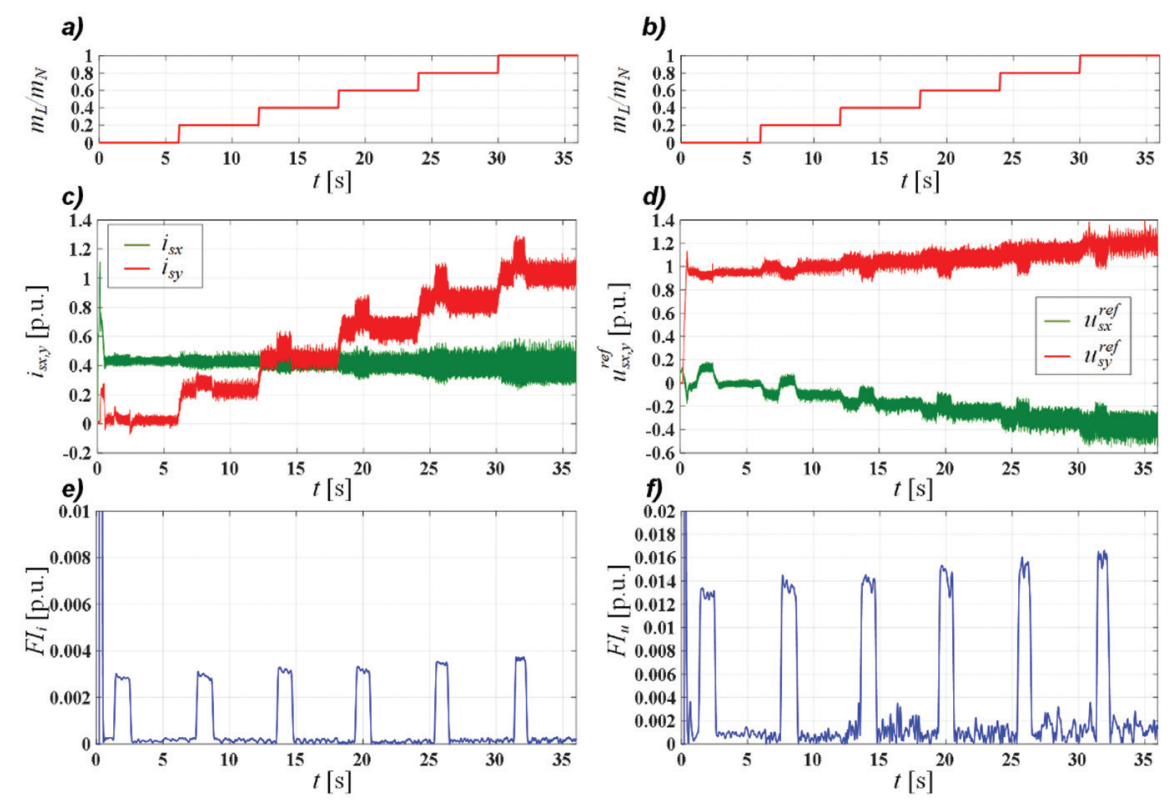

Fig. 7. Waveforms of state variables and diagnostic indicators in the case of: constant, rated speed and changing load torque, cyclic momentary short-circuits of five turns: $(a, b)$ load torque, (c) current vector components in a synchronous system, (d) voltage vector components in a synchronous system, (e) current indicator, and (f) voltage indicator.

second component of the vector increases with increasing motor torque (Figure 7c). The components of the stator voltage vector change according to the operating point and result from the operation of the current component regulators (Figure $7 \mathrm{~d}$ ).

Five shorted turns were physically modelled for each load torque value. Momentary changes of instantaneous values can be noted in the waveforms of current and voltage vector components, but they are so small (and in the actual drive may depend on the operating conditions) that they obviously cannot be used for the diagnosis the condition of the induction motor.

When analysing and comparing the signals mentioned above, the proposed diagnostic indicators shown in Figures $7 \mathrm{e}$ and $7 \mathrm{f}$ can effectively be used for assessing the condition of the motor windings.

The difference between the indicator values in undamaged and damaged conditions is clearly observed. It can also be noted that the values of the indicators are similar regardless of the torque value.

\subsection{Dependence of the suggested diagnostic indicators on the load torque and the angular speed of the motor}

A large number of experimental studies were carried out to demonstrate the dependence of the proposed diagnostic indicators on the number of shorted turns $N_{s h}$, drive speed $\omega_{m}$ and load torque $m_{L}$. The test results obtained are shown in Figure 8 in the form of 3-D characteristics. The values of the $\mathrm{Fl}_{i}$ (Figures 8a and $8 \mathrm{c}$ ) and $\mathrm{Fl}_{u}$ (Figures $8 \mathrm{~b}$ and $8 d$ ) in function of the speed (Figures $8 a$ and $8 b$ ) and the load torque (Figures $8 c$ and 8d) are shown, respectively. It is clear that in each case the value of both indicators increases with the increasing number of shorted turns. The sensitivity of the current indicator (Figure 8a) decreases with increasing speed, while the effect is opposite in the case of the voltage indicator (Figure $8 b$ ). Diagnostics of the stator windings of the induction motor using a voltage indicator should be carried out at high speeds, preferably close to the rated one. The current indicator can be used more efficiently at lower speeds.

As shown in Figures $8 \mathrm{c}$ and $8 \mathrm{~d}$, the proposed damage indicators do not depend on the load torque - their levels are constant for constant torque; they only increase with the increasing degree of the damage.

\subsection{Impact of PI controllers parameters on the diagnostics of induction motor damage}

As stated above, the field-oriented control system tends to compensate the damage because of the action of regulators and feedbacks. Figure 9 shows the influence of the controller parameter values on the obtained current 

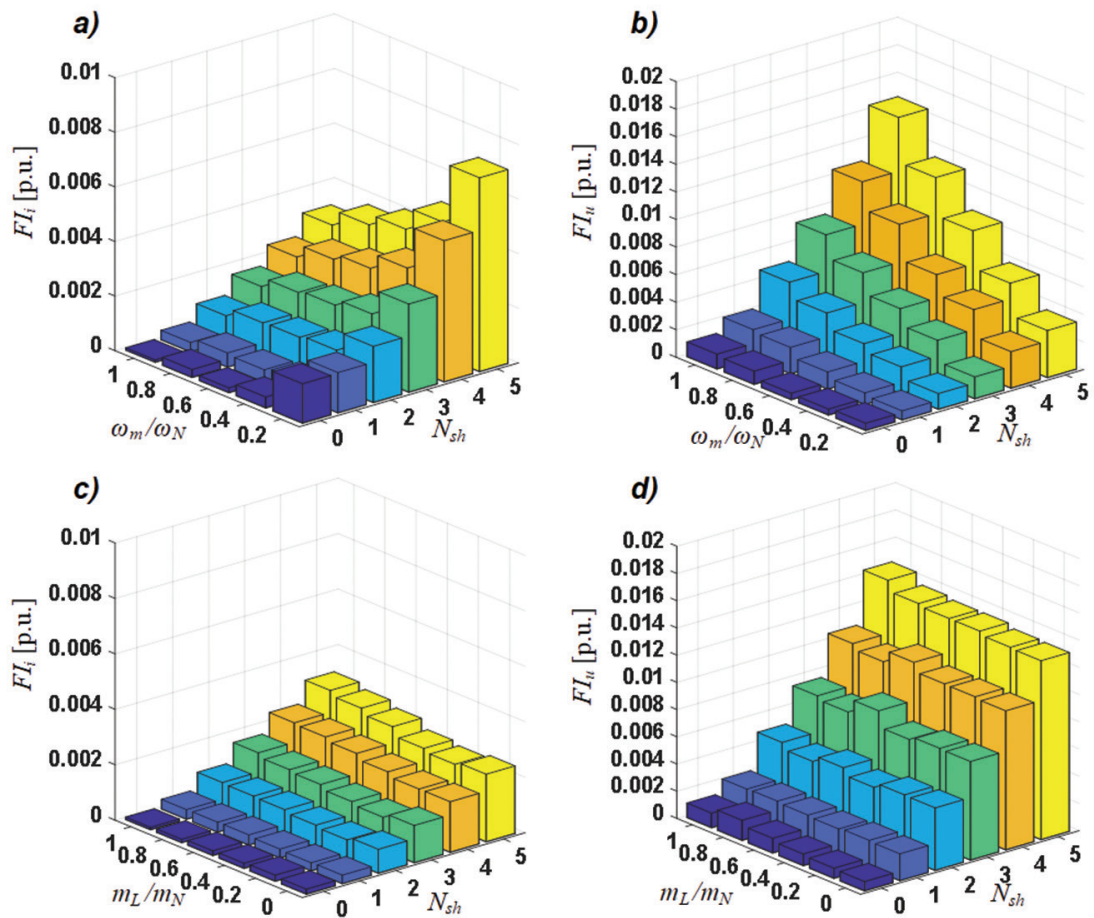

Fig. 8. The relationship between the diagnostic indicators and the number of shorted turns, and: (a, b) motor speed (with the rated torque); (c, d) load torque (with the rated speed); (a, c) current indicator; (b, d) voltage indicator.
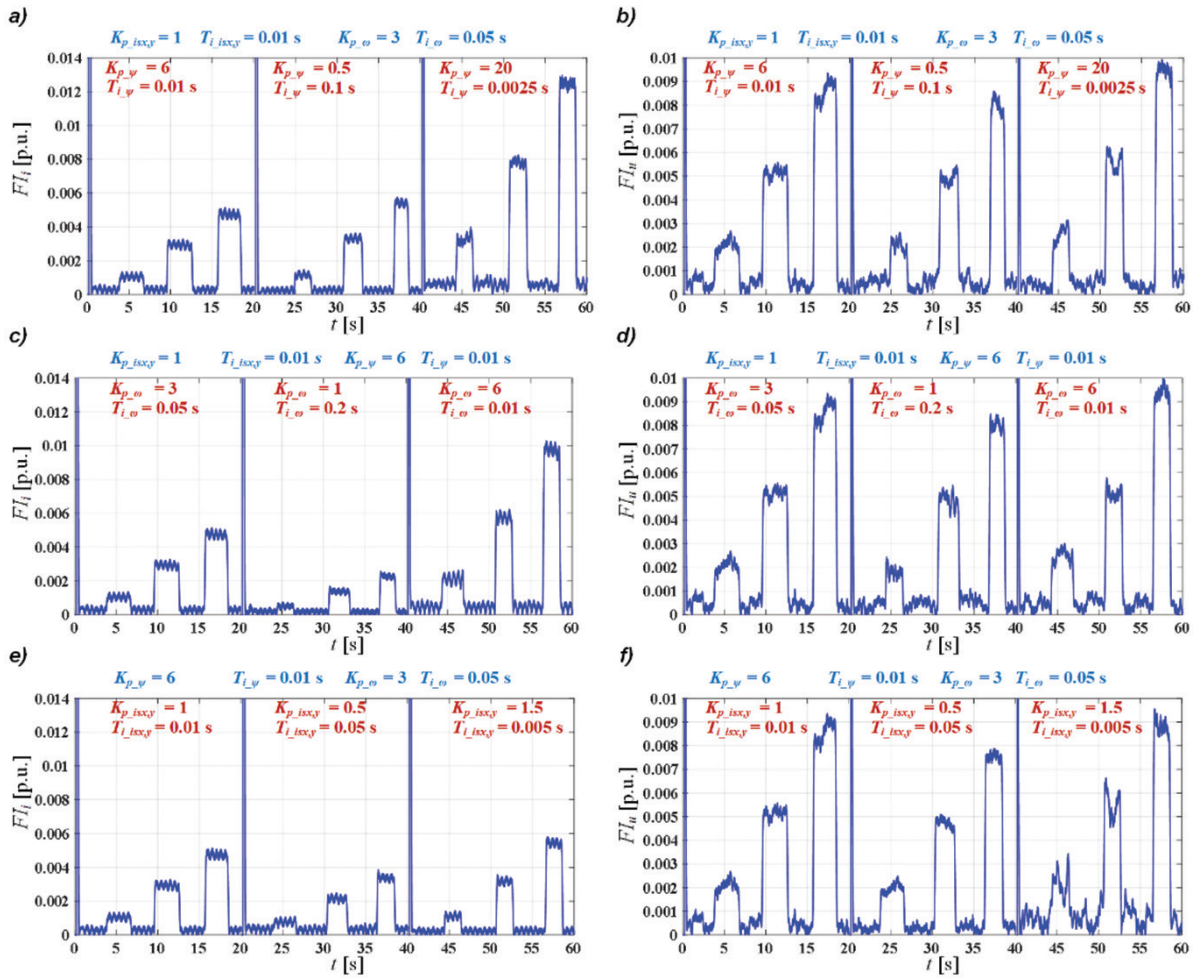

Fig. 9. Impact of regulator parameters on the received diagnostic indicators' values during a short-circuit of one, two, three turns, respectively, at a speed of $0.25 \omega_{N}$ and a torque of $0.5 m_{N}$. $(a, b)$ the effect of changing the flux regulator parameters; (c, d) the effect of changing the speed regulator; $(e, f)$ the effect of stator current vector components regulators' parameters changing; $(a, c, e)$ current indicator; (b, d, f) voltage indicator. 
(Figures 9a, 9c, and 9e) and voltage (Figures 9b, 9d, and 9f) Fls. It is assumed that the parameters of the regulators of both current vector components were changed simultaneously. During the research, the following form of a PI regulator transfer function is assumed:

$$
G_{P I}(s)=K_{p}\left(1+\frac{1}{T_{i} s}\right)
$$

First, second and third rows of Figure 9 shows the effect of flux, speed and current regulator parameters varying, respectively. The parameter values in each drawing were changed approximately every $20 \mathrm{~s}$, according to the legend in red in the drawings. The current indicator is the indicator that mostly responds to changes in regulator parameters. In general, the greater the value of the gain parameters of the flux and speed controllers $\left(K_{p \psi}, K_{p \omega}\right)$ and the smaller the value of time constants $\left(T_{i \psi}, T_{i \omega}\right)$, the greater the value of the current indicator obtained. The parameters of the current component regulators do not significantly affect $\mathrm{FI}_{i}$.

On the other hand, as shown in Figures 9b, 9d, and 9e, the voltage indicator does not react to the changing parameters of the regulators. Because of this reason, it can be considered that it is more suitable for diagnosing stator windings damage than the current indicator (user of the industrial converter often can change the parameters of regulators).

\section{Summary}

The article presents the results of research on detecting damage to an induction motor powered by a frequency converter controlled in a closed control structure (DFOC). A new method of induction motor stator damage's diagnostic has been suggested, allowing for the abandonment of time-consuming FFT analysis.

The presented results of the tests confirm that the proposed diagnostic indicators can be used effectively to detect short-circuit turns of a motor operating in a closed control structure. The analysed current and voltage signals subjected to a modified Park transformation allow extracting of a constant value containing the information about the fault. An increase in the diagnostic indicator amplitude at given operating conditions indicates that a winding shorted turns damage has occurred in the stator windings. It is worth noting that the proper correlation of the voltage indicator with the current indicator, with the constant parameters of the controllers, allows diagnosing the motor in the entire speed range.

The undoubted advantage of this method is the ability to diagnose the motor when the load torque is close to zero. Moreover, the diagnostic coefficient values are insensitive to both the power angle and the angular shift between the first and third current harmonics when compared to the first harmonic.

However, it should be noted that a change in the parameters of controllers located in the control structure affects the change in the value of the current indicator, while not affecting the voltage coefficient, which should be taken into account when correlating these two indicators.

Further research will also include an analysis of the possibility of locating the place where the shorted turns damage occurs (motor phase in which the damage occurs) by analysing the obtained constant components in the $\alpha$ and $\beta$ axis of the analysed vectors.

\section{Acknowledgements}

This research was supported by statutory funds of the Department of Electrical Machines, Drives and Measurements of the Wroclaw University of Science and Technology.

\section{ORCID ID of the authors}

Grzegorz Jakub Tarchała: ORCID iD 0000-0001-7457-9674 <https://orcid.org/0000-0001-7457-9674>

Marcin Wolkiewicz: ORCID iD 0000-0003-1197-8517<https://orcid.org/0000-0003-1197-8517>

Mateusz Stanisław Krzysztofiak: ORCID iD 0000-0002-6184-3808 <https://orcid.org/0000-0002-6184-3808> 


\section{References}

Bednarz, S. A. (2017). Rotor Fault Compensation and Detection in the Sensorless Induction Motor Drive. Power Electronics and Drives, 2(37), pp. 71-80.

Bellini, A., Filippetti, F., Franceschini, G. and Tassoni, C. (2000). Closed-Loop Control Impact on the Diagnosis of Induction Motors Faults. IEEE Transactions on Industry Applications, 36(5), pp. 1318-1329.

Bellini, A., Filippetti, F., Tassoni, C. and Capolino G.-A. (2008). Advances in Diagnostic Techniques for Induction Machines. IEEE Transactions on Industrial Electronics, 55(12), pp. 4109-4126.

Boileau, T., Leboeuf, N., Nahid-Mobarakeh, B. and Meibody-Tabar, F. (2013). Synchronous Demodulation of Control Voltages for Stator Interturn Fault Detection in PMSM. IEEE Transactions on Power Electronics, 28(12), pp. 5647-5654.

Cruz, S. M. A. and Cardoso, A. J. M. (2001). Stator Winding Fault Diagnosis in Three-Phase Synchronous and Asynchronous Motors, by the Extended Park's Vector Approach. IEEE Transactions on Industry Applications, 37(5), pp. 1227-1233.

Cruz, S. M. A. and Cardoso, A. J. M. (2004). Diagnosis of Stator Inter-Turn Short Circuits in DTC Induction Motor Drives. IEEE Transactions on Industry Applications, 40(5), pp. 1349-1360.

Diallo, D., Benbouzid, M. E. H., Hamad, D. and Pierre, X. (2005). Fault Detection and Diagnosis in an Induction Machine Drive: A Pattern Recognition Approach Based on Concordia Stator Mean Current Vector. IEEE Transactions on Energy Conversion, 20(3), pp. 512-519.

Drif, M. and Marques Cardoso, A. J. (2014). Stator Fault Diagnostics in Squirrel Cage Three-Phase Induction Motor Drives Using the Instantaneous Active and Reactive Power Signature Analyses. IEEE Transactions on Industrial Informatics, 10(2), pp. 1348-1360.

Gandhi, A., Corrigan, T. and Parsa, L. (2011). Recent Advances in Modelling and Online Detection of
Stator Interturn Faults in Electrical Motors. IEEE Transactions on Industrial Electronics, 58(5), pp. 1564-1575.

Grubic, S., Aller, J. M., Lu, B. and Habetler, T. G. (2008). A Survey on Testing and Monitoring Methods for Stator Insulation Systems of Low-Voltage Induction Machines Focusing on Turn Insulation Problems. IEEE Transactions on Industrial Electronics, 55(12), pp. 4127-4136.

Orłowska-Kowalska, T. and Dybkowski, M. (2016). Industrial Drive Systems. Current State and Development Trends. Power Electronics and Drives, 1(36), pp. 5-25.

Riera-Guasp, M., Antonino-Daviu, J. A. and Capolino, G.-A. (2015). Advances in Electrical Machine, Power Electronic, and Drive Condition Monitoring and Fault Detection: State of the Art. IEEE Transactions on Industrial Electronics, 62(3), pp. 1746-1759.

Seshadrinath, J., Singh, B. and Panigrahi, B. K. (2014). Investigation of Vibration Signatures for Multiple Fault Diagnosis in Variable Frequency Drives Using Complex Wavelets. IEEE Transactions on Power Electronics, 29(2), pp. 936-945.

Wolkiewicz, M., Tarchała, G. and Kowalski, C. T. (2015). Stator Windings Condition Diagnosis of Voltage Inverter-Fed Induction Motor in Open and ClosedLoop Control Structures. Archives of Electrical Engineering, 64(1), pp. 67-79.

Wolkiewicz, M., Tarchała, G., Kowalski, C. T. and Orłowska-Kowalska, T. (2017). Stator faults monitoring and detection in vector controlled induction motor drives-comparative study. In: Kabziński, J. ed., Advanced Control of Electrical Drives and Power Electronic Converters. Studies in Systems, Decision and Control, Vol. 75. Cham, Switzerland: Springer, pp. 169-191.

Wolkiewicz, M., Tarchała, G., Orłowska-Kowalska, T. and Kowalski, C. T. (2016). Online Stator Interturn Short Circuits Monitoring in the DFOC InductionMotor Drive. IEEE Transactions on Industrial Electronics, 63(4), pp. 2517-2528. 